\title{
Preliminary Exploration on the Internationalized School-running Strategies of Higher Vocational Colleges in the Context of the "Belt and Road Initiative"
}

\author{
—Taking Speciality Group of Automobile Intelligent Manufacturing as an Example \\ Qing-song Zhu* \\ School of Automotive Engineering \\ Beijing Polytechnic \\ Beijing, China \\ Qingsong111@163.com \\ Rui-can Hao \\ School of Automotive Engineering \\ Beijing Polytechnic \\ Beijing, China \\ haoruican@163.com
}

\author{
Jing Wang \\ School of Automotive Engineering \\ Beijing Polytechnic \\ Beijing, China
}

\begin{abstract}
The purpose of the paper is to explore the internationalization strategy of Higher Vocational Colleges under the background of "one belt and one road". By taking the opportunity of promoting the national strategies, combining school-running characteristics, professional resource superiority and taking the internationalized construction of automobile intelligent manufacturing specialty group as a pilot project, the paper explores the implementation of "Six Internationalizations" strategy. The internationalization of teaching concept, professional standards, teaching staff, resource management, teaching environment and the skill competitions. It was concluded that after the establishment of the frame-work of "Six Internationalizations" system, the internationalized schoolrunning strength and international influence of the speciality group have been greatly enhanced.
\end{abstract}

Keywords-Belt and Road Initiative; Higher Vocational Colleges; Internationalization; School-running

\section{INTRODUCTION}

In the context of the indepth implementation of the "Belt and Road Initiative" of our country and the vigorous development of the new round of industrial and technological revolution in the world, the policies of building and sharing "cooperation in education interconnection and interworking as well as talent cultivation and training, and a silk road cooperation mechanism" together with the countries along the road point out the direction for education, construct the cooperation framework and work out the action plan. The construction of the "Belt and Road Initiative" not only provides the excellent development opportunity for higher

Thanks to the fund and support from the general program of Beijing Municipal Education Commission (KM201910858005). vocational education, but also brings the historical mission of cultivating internationalized high-skilled talents.

According to the 2017 National Statistical Bulletin on the Development of Education, China now has 1388 higher vocational (colleges) institutions with 11,049,549 internal students. China has become the largest country of higher vocational education in the world. The Decision of the State Council on Accelerating the Development of Modern Vocational Education proposed to strengthen international exchanges and cooperation. The Action Plan for Innovation and Development of Higher Vocational Education (2015-2018) also stressed the introduction of overseas high-quality resources, the expansion of the international influence of vocational education and other guiding opinions. International cooperation and exchanges have become an effective path for overtaking and catching up with the internationalized trend. It has become an inevitable choice for China's higher vocational colleges to embark on the road of internationalized schoolrunning.

\section{INTERNATIONALIZED SCHOOL-RUNNING STRATEGIES AND MEASURES}

\section{A. Overall Line of Thinking}

By taking the internationalized construction of the automobile intelligent manufacturing specialty group of our school as an example, taking the opportunity of promoting the national "Belt and Road Initiative" strategies by our school, starting from the thorough external training project and the Thai student project and combining schoolrunning characteristics and professional resource superiority, the 
following explores the implementation of "Six Internationalizations" strategy. The internationalization of teaching concept, professional standards, teaching staff, resource management, teaching environment and skill competitions. The framework of "Six Internationalizations" system is established preliminarily, which lays a solid foundation for internationalization in the later stage.

\section{B. Specific Measures}

1) Establishing International Standards for the Cultivation of High-end Technical and Skilled Talents: We draw on advanced concepts in vocational education and teaching from developed countries such as Germany, Britain and Japan, base ourselves on the deep foundation of order training in 13 years with Beijing Benz Automotive Co., Ltd., study and work out international training standards for highend technical and skilled talents for automobile intelligent manufacturing post groups together with many research institutions and groups such as SAE-China, China Industry Innovation Alliance for the Intelligent and Connected Vehicles and National New Energy Vehicle Technology Innovation Center, set up the automobile intelligent manufacturing vocational warehouse and curriculum system keeping up with the development of the automobile industry, incorporate advanced elements of some industries such as "four new technologies" (new technology, new process, new materials and new equipment) and new norms into the teaching standards and teaching content, implement international standards for training highend technical and skilled talents so as to promote cultural exchanges between China and Thailand by starting with the Sino-Thai "2+1" international student training cooperation project, and explore the promotion to other "Belt and Road" countries.

2) Introducing High-quality Resources to Meet International Standards for Vocational Qualification Certification: On the basis of indepth cooperation with GFBM, Motor Industry Research Association, Daimler Greater China Investment Co., Ltd. and Beijing Benz Automotive Co., Ltd., we improve the German POCC certificate and the British IMI certificate training mechanisms to improve the teaching and employment quality of vocational education, introduce the British EAL Certificate (British Engineering Manufacturing Apprenticeship Certification Authority), deepen exchanges and cooperation with British universities, initially establish a mechanism through EAL level-by-level certification integrating Chinese vocational education and British higher education so as to provide students with access to overseas study, expand students' employment and enhance the employment level, participate in the research and formulation of international standards for EAL and IMI vocational education, and explore the establishment of international vocational qualification certification training subcenters in "Belt and Road" countries.
3) Building a Team of Double-qualified and Bilingual International High-end Professional Teachers through Both Introduction and Training: We introduce from enterprises or universities foreign industry experts with profound professional level and firstclass English as the leaders of internationalized teachers, cultivate a team of internationalized teachers under Sinoforeign cooperation, full-time and parttime combination, strengthen the training of double-qualified and bilingual professional teachers, and continue to promote indepth visit and exchange projects for teachers and students with wellknown foreign universities and vocational colleges, such as The South Westphalia University of Applied Sciences, Helsinki Vocational and Technical College of Finland and HTL Braunau, actively create opportunities for teachers to exchange and study abroad, expand their international vision, learn advanced international educational and teaching concepts and improve their foreign language proficiency, send 10 teachers a year to exchange and study abroad, build the platform of professional technical skill training, open up the channels of obtaining certificates of international technical skill levels, and perfect the concrete operation mechanism of enterprise practice under teachers so that the ratio of doublequalified teachers can reach more than $95 \%$ and a team of 15 20 double-qualified and bilingual teachers can be formed within five years.

4) Building a Platform for Internationalized Vocational Education and Teaching Re-sources through Interconnection and Sharing: We focus on key points, improve the quality and level of international exchanges and cooperation, further comb the existing international cooperation projects, conduct appropriate screening and focusing on the basis of the existing relevant curriculum system and certification system introduced from Germany and Britain, deepen the connotation of cooperation projects, actively cooperate with domestic well-known enterprises such as Beijing Benz and Daimler, set up the skill training course system and international education and teaching resource sharing platform for industrial robotics, vehicle detection and maintenance technology and new energy vehicle technology, take the going global strategy with famous multinational enterprises such as BAIC Group and CAIC Inter-national, and promote professional teaching standards, curriculum system and related teaching resources of industrial robotics, and vehicle detection and maintenance technology in "Belt and Road" countries.

5) Creating an atmosphere for internationalized vocational education and teaching by remodeling space: In order to create the environment, we integrate elements such as internationalized teaching concepts, teaching modes and qualification standards, carry out international understanding and international pluralistic education for teachers and students according to the cooperation and exchange countries to train their international vision and consciousness, adopt the bilingual mode in the media propaganda, system construction, teaching design and so on. We should respect international 
habits, establish bilingual library, coffee shop and international student activity center, introduce international advanced equipment and advanced technology and process for the majors enrolling foreign students and carrying out training for foreign employees, perfect the relevant experimental and training conditions for the majors, establish and perfect the matching teaching management mechanism for foreign students.

6) Cultivating High-end Technical and Skilled Talents through Sino-foreign Cooperation in International Vocational Education: We actively explore the indepth exchanges and cooperation with "Belt and Road" countries, deepen cooperation with Min Buri Institute of Technology of Thailand on the basis of the cooperation between China and Thailand through " $1+2$ " in the field of industrial robotics, expand the scope and scale of majors enrolling overseas students. For other "Belt and Road" countries, we develop overseas student education in majors such as automotive manufacturing and assembly technology, vehicle detection and maintenance technology, enroll 30 overseas students on average every year within five years, cooperate with BAIC Group, CAIC International and other multinational enterprises, jointly carry out the training of foreign highend technical and skilled talents on the basis of Beijing Benz Institute of Automobile Manufacturing Engineers, explore the overseas joint establishment of technical and skilled training bases, establish "automobile intelligent manufacturing Luban workshop", provide international vocational education services, and undertake education and training for overseas staff of Chinese enterprises when implementing "going global" strategy.

7) Incubating the World's First-class Technology and Skill Competition Team with Craftsmanship: We will improve the selection and training mechanism for the members of innovation societies such as ST team and industrial robotics application innovation team, constantly improve the scientific research facilities of the racing club, racing workshop and industrial robot engineering center as well as related hardware and software conditions, strengthen the exchanges and cooperation between the team and innovation teams of universities such as Tsinghua University and Beijing University of Technology, continuously improve the overall technical skills and comprehensive quality of the team, incubate the racing team and innovation team reaching the world's technical skill level, participate in the FSAE each year --the United States BAJA Competition and the BRIC Skill Competition and other related world technical skill competitions, vigorously improve the international competition ability and level of teachers and students of speciality group and enhance the international reputation of speciality group through international competitions and technical skill exchanges.

Fig. 1 shows the 3rd runner-up of the most important and valuable endurance event in the Baja World University
Competition. It is also the best result of the Chinese team in the past years. The Baja ST team from the School of Automotive Engineering of Beijing Polytechnic went to Rebeck, Los Angeles, USA on May 13-21, 2019 to participate in the Baja World University Auto Competition.

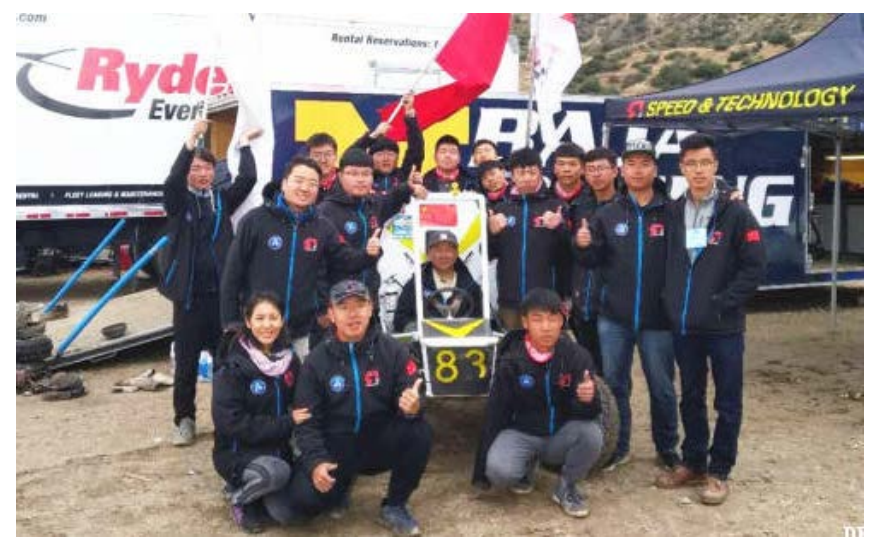

Fig. 1. ST team competes in the United States

\section{SUMMARY}

In the context of the "Belt and Road Initiative" and a new round of global industrial and technological revolution, this paper initially explores the internationalized school-running strategies, constructs the preliminary framework of internationalized school-running system of higher vocational colleges from the internationalization of teaching concept, the internationalization of professional standards, the internationalization of teaching staff, the internationalization of resource management, the internationalization of teaching environment and the internationalization of skill competitions respectively, and contributes to the training of internationalized talents.

\section{ACKNOWLEDGMENT}

Thanks to the fund and support from the general program of Beijing Municipal Education Commission (KM201910858005).

\section{REFERENCES}

[1] Yi Zhoujie, “The Exploration of the Way of Internationalized School Running Mode of Higher Vocational Colleges in China against the Background of 'The Belt and Road' ”, Foreign Economic Relations \& Trade, vol. 11, pp. 131-133, 2018 (In Chinese)

[2] Zhao Li, "Current Situation and Analysis of Internationalization of Higher Education in China”, Journal of Tianiin Vocational Institutes, vol. 21(1):106-110, 2018 (In Chinese)

[3] WU Chen, "The Reform of Organizational Structure on the Internationalization of Higher Education in the Background of 'Double First-class': From the Perspective of 'AGIL Schema' of Structural Functionalism”, Chongqing Higher Education Research, http://kns.cnki.net/kcms/detail/50.1028.g4.20181203.1113.002.html, 2018-12-03 11:13:39 (In Chinese)

[4] GUO Bin, XU Jing, "Research on the Internationalization of Undergraduate Education and Higher Vocational Education in China in Recent Ten Years”, SHEN Jun-1ong. Journal of Liaoning Higher Vocational, vol. 21(2), pp. 10-15, 2019 (In Chinese) 
[5] Liu Jianfei, Chen Bin, "Analysis of the International School-running Model and Guarantee Measures of Higher Vocational Colleges", Chinese Vocational and Technical Education, vol. 34, pp. 84-87, 2018 (In Chinese)
[6] CHEN Yu. QIN Wei-xing, TANG Hong-min, "Internationalization of Teachers Based on the Chinese-foreign Jointed Education Program”, Education Teaching Forum, vol. 12, pp. 28-29, 2019 (In Chinese) 